\title{
ARE ECONOMIC STUDIES GRADUATES UNDER-EMPLOYED? A SKILLS MISMATCH STUDY
}

\author{
Roxana Hatos*, Tomina Săveanu \\ Research Centre for Competitiveness and Sustainable Development, Faculty of Economic \\ Sciences, University of Oradea, Oradea, Romania \\ rhatos@uoradea.ro \\ tsaveanu@uoradea.ro
}

\begin{abstract}
Skills mismatch is a generic term that refers to various types of imbalances of skills and competencies offered and those needed in the labour market. The concept has become one intensely discussed and subjected to measurements in research amid international concerns about its human resource under-utilization. The article aims to analyse under-employment of economic studies graduates. This is achieved by analysing the results of a professional path survey, with bachelor graduates of Faculty of Economics, University of Oradea, conducted at the end of 2015. Our main research question was: which are the predictors of the over-qualification of University of Oradea. Faculty of Economic Sciences graduates. The analyses show that under-employment of our graduates is not explained by any demographic variables, but solely by employment outside the domain and specialization of education, as well as by number of jobs previously held by respondents.
\end{abstract}

Keywords: employment; skills mismatch; labour market integration; economic studies graduates, Oradea.

JEL classification: J2; J24; J21.

\section{Theoretical overview}

The recession started in 2008-2009 produced a significant increase of the unemployment rate in the countries from the European Union. Nonetheless, studies on European employers report difficulties in hiring for their available open positions. The study on European companies conducted in spring 2013 revealed that $40 \%$ of companies face difficulties in finding employees with proper qualification (CEDEFOP-European Centre for the Development of Vocational Training, 2014). Several researches that reach the same surprising conclusion - that despite a high unemployment rate a high number of jobs to not find adequately trained personnel - identify also some of the reasons: the lack of technical competences of the candidates or the absence of workplace skills (CEDEFOP, 2014).

The skills mismatch is a generic term referring to various types of unbalances between the abilities and competences offered and the ones needed on the labour market (Allen and van der Velden, 2001). The concept became intensely debated and researched internationally in the context of the concerns regarding the human resources underutilization (ILO-International Labour Office, 2014).

The main types of asymmetry referred to in the literature and in the related policies, are the following:

- Scarcity or abundance of skills/competences - when the supply (or demand) of a certain skill/competence exceeds demand (or supply);

* Corresponding author 
- Skills gap - the type and level of skills/competences are different than the ones requested in order to perform at work;

- Vertical asymmetry - the educational level or qualification is higher or lower than the one needed;

- Horizontal asymmetry - the type/domain of education and the skills/ competences are in another field than the one requested;

- Over-qualification / under-qualification - employees have higher or lower degrees/qualifications than the ones needed for the job;

- Obsolescence of skills / competencies - skills and competencies used at work are no longer needed or has deteriorated over time.

As skills and competences are rarely measured as such, through direct indexes, the measure of skills mismatch is conducted mainly using proxies, with their advantages and disadvantages. For example, measuring the asymmetry between supply and demand on the labour force based on the comparison between the structure of educational achievements of the people employed and unemployed. may show clearly which is the educational level and the areas of specialization which are in deficit (ILO, 2013).

According to the comparative data, vertical asymmetry affects half of the active people on the Romanian labour market, under-education was approximately two times higher, before the crisis, then over-education among youth (Hatos, 2015).

Factors that are considered to influence the quality of employment, as analysed also in this paper are the following:

Gender

Generally experience, including the one related to research is considered a disadvantage of women on the labour market. This is due firstly to the discrimination of women motivated by their apparent shorter integration on their jobs due to their extra domestic chores. Employers show, some degree of prudence in hiring women as they expect maternity leaves and other situations of absence due to maternity. Underemployment can also be the effect of similar expectations of women themselves. They accept traditional gender roles focusing on domestic tasks and thus have lower professional aspirations and accept much easier jobs that underuse their skills. Consequently, we expect that the risk of underemployment will be higher for women (Castellano, Longobardi and Rocca, 2014).

Marital status and number of children

Regarding marital status we can formulate contradictory hypotheses. In the traditional model, marriage represents a moment in a person's life cycle in which social identities and roles get settled, as a consequence of previous searches pursuing personal aspirations. Thus, it is expected that married persons have stable and satisfactory jobs, the correlation between marital status and the quality of employment should be positive. Nonetheless, in the modern view, marriage and carrier are often seen as contradictory, which explain delaying marriage until a older age in advanced economies (Muresan, 2014). Consequently, we can formulate the hypothesis that between being married and the quality of employment there will be a negative relation.

Same logic can be used for the relation between the number of children and quality of employment: in a traditionalist manner, the relation should be positive, yet in a modern view we would rather expect a negative relationship (Muresan, 2014).

Age at getting the degree

The age of the person obtaining a higher degree (BA in our case) may determine many of the results of education on the labour market, and the hypotheses that may be stated are not convergent. The older the graduate, the higher the probability that during his or her studies he/she had also other duties (in household or work) which prevented the full participation at classes. Consequently they would have lower educational results then the traditional students (fresh graduates of high-school) which would lead to lower results of their integration on the labour market. 
On the other hand, non-traditional older students benefit during their studies of direct experience from the labour market, which facilitates the assimilation of knowledge and competences directly relevant on the market. More, work experience can constitute an advantage in finding a job after graduation. In this regard one study reveals that active students: employed, volunteering in a NGO or a company, are also the ones showing higher levels of school engagement (Saveanu and Saveanu. 2013). School engagement is showed to give a better insight to students regarding their job expectations and also to facilitate a better school-to-work transition (Saveanu and Saveanu, 2012).

According to the first argument we would expect that the older the age, the higher the chances for underemployment. In the second argument, the relation between age and quality of work would be positive.

Year of graduation

In this regard the dependence is direct: the longer the period after graduation the smaller the chance of underemployment, as the person had a more time to find other jobs according to their education (Chevalier and Lindley, 2009).

\section{School involvement}

Clearly, one of the most plausible predictors of professional success is school achievement (Becker, 1964). This is determined by intelligence, motivation and other resources which determine in the same direction also the performance in finding and practicing a profession (Kim and Kim, 2003; Reimer, Noelke and Kucel, 2008). Our study did not directly measure school results in grades from high-school or university, due to obvious reasons: great biases produced by indirect surveys in this matter. However, educational involvement engagement was measured using three external correlated indexes: number of degrees, $\mathrm{BA}$ and MA, obtained by the respondent, participation in practical training and counselling, and whether they have graduated the economic high-school.

Even if we would expect for each of these variables a positive relationship with the quality of engagement, there are reasons to expect negative correlations. There are studies that show that a higher number of diplomas acquired by a person are motivated by finding compensation in the area of accreditations for the lack of other qualities needed on the labour market, a phenomenon that produces over qualification (van de Werfhorst, 2011). In the same manner we can argue for the relation of over-qualification with the participation in practical training and counselling activities. Especially in the case of the latter, but also in the case of voluntary practical training, these can have a compensatory and therapeutic role, indicating problems of integration on the labour market replacing other capabilities. Finally, it is possible that the economic profile at the high-school level is not chosen for vocational reasons but also rational, given the fact that is a higher competition at other specializations with an academic profile, while the graduation of such a profile gives more problems on the labour market.

\section{Specialization}

It is well known that the economic and psychological rewards of economic specializations are not identical. If this was the case, and the choice of one specialization would be based solely on vocational criteria, probably the competition at annual admissions would be less prominent. In fact, the attractiveness of different specializations reflects future different expected rewards and reveals different evolutions of corresponding jobs. An increasing number of studies report a strong relation between graduates' risk of over-education and cyclical and structural dimensions of the demand and the supply of skilled workers (Hannan, Raffe and Smyth, 1997; Ortiz, 2006; Verhaest and van der Velden, 2013).

Correspondence between the field of study and the field of work

As we have seen in our sample, almost a third of graduates work in unrelated fields as their studies. As the level of study is one of higher education it is less likely that our graduates work in other higher education fields (such as engineering, psychology) and consequently it is more probable that they are under-employed. The risk of over-education is found to be smaller among graduates from technical and scientific fields than among 
graduates from the social sciences and humanities (Barone and Ortiz, 2011; Barone and Schindler, 2014).

\section{Skills mismatch of students from Oradea in the field of economics 2.1. Methodology of the study}

This article aims to analyse the correlates of under-employment of the graduates of Faculty of Economics, University of Oradea. This objective is investigated using the data of a survey of the professional path (tracer) of BA graduates of the Faculty of Economics conducted in the end of 2015, based on 165 answers. The instrument of analyses was the questionnaire that was accessible online and was distributed to graduates using the graduate's lists of the faculty teachers, the online networks and the personal contacts list of the authors. Due to this aspect, our research has to be treated in its methodological limits. Our analysis firstly presents the results of the findings regarding skills mismatch of our respondents and in the second part investigates the covariates of underemployment. The validation of hypotheses was conducted using a multiple logistic regression model of the probability that the student declares he was over-qualified, compared to the situation in which he declares he is under-qualified. This part of the analysis was based on 151 cases from our survey, as $8 \%$ were excluded due to nonresponses.

\subsection{Skills mismatch}

The percentage of those who consider themselves over-qualified is almost three times higher than those under-qualified. More than half (56\%) of the students answering the survey consider that they have tasks according to their qualification while $13 \%$ declare that they are overemployed and $32 \%$ are underemployment. Significant from this point of view is that solely $25 \%$ of our subjects declare that they used at their work, to a high of very high degree, the skills acquired at school. On the other hand, $40 \%$ declare that they used in their work only in a small or very small percentage the information acquired during their studies, while a third of the respondents could not decide upon the matter.

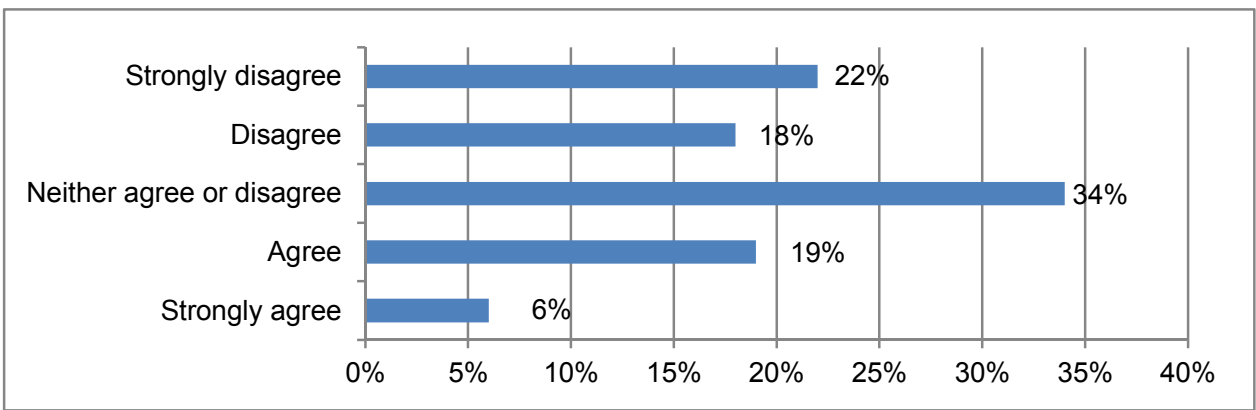

Figure 1: To what extent to you consider that you could use the information and skills acquired during your BA program at your first job after graduation?

On the other hand, it is important to note that more than half of the graduates holding a job declare that it is in their educational field or even in the area of expertise. This information contradicts the main assumption that young graduates of higher education have inappropriate jobs. As in the case of under-qualification - which affects a third of our graduates - these data can be affected by sampling biases: it is likely that the availability to take part in the survey was higher for students which did not have difficulties in finding a job in their field. 


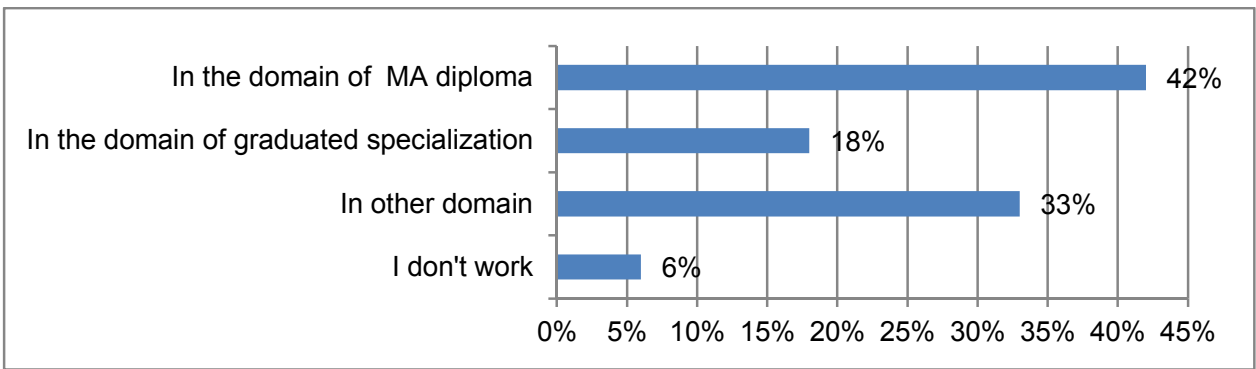

Figure 2: Your current job is related to your educational field (\%)

\subsection{Covariates of skills mismatch}

Our main research question was: which are the predictors of the over-qualification of University of Oradea. Faculty of Economic Sciences graduates? In order to answer this question we first describe the variables used and consequently present and discuss the logistic regression model.

Dependent variable

The correlation of the level of qualification required by the job and the higher education was measured using a dichotomous variable, in which value 1 refers to overqualified situation. The majority of respondents declared a correspondence between education level and the qualification required by their jobs as well as under-qualification situations.

Table 1: Over-qualification of graduates

\begin{tabular}{|l|l|}
\hline & $\mathbf{N} \%$ \\
\hline Adequate or under-qualification & 69 \\
\hline Over-qualification & 31 \\
\hline
\end{tabular}

\section{Independent variables}

Regarding gender, men represent in our subsample only $28 \%$ of respondents, reflecting the higher percentage of female graduates of economic sciences. Most of our respondents gained their bachelor diploma in economic sciences at the age of 22 and $90 \%$ obtained the diploma before the age of 25 , showing that most of our students are traditional. While the median age of getting the diploma is 22 , the average age is of 23 , proving the small incidence of non-traditional students.

Their marital status is in most cases unmarried (65\%), nonetheless $29 \%$ are married, $4 \%$ engaged and $3 \%$ divorced.

The majority our respondents have no children (88\%), while $7 \%$ have 1 child, $4 \%$ two children and $2 \%$ have three. The number of children correlates with the marital status.

Over $50 \%$ of our graduates obtained their diploma after 2008 - most of them gained it between 2012 and 2015.

The average number of diplomas of one respondent is of 1.7 , while the median is of 2 diplomas. Actually, most subjects have maximum 2 diplomas, half of them having one BA and one MA diploma as follows: $40 \%$ have 1 diploma. $51 \%$ have 2 diplomas. $8 \%$ have 8 diplomas, $1 \%$ have 4 diplomas and $1 \%$ have 5 diplomas.

Regarding the involvement in practical training and counselling, solely $9 \%$ of the people answering the questionnaire declared that they did not participate in any of such activities. $55 \%$ of the graduates participated in at least one of the following: mandatory practical training, practical training offered by the Faculty within a European funded project, voluntary practical training and counselling. A high number (31\%) participated in two of these activities, while $6 \%$ participated in three.

Considering their previous studies, $47 \%$ of our subjects graduate economic profile highschools, showing that the main selection pools for our students are profile related schools. 
Regarding the work experience, we have eliminated from this analysis the people that did not have any jobs ( $3 \%$ of the sample). In average, graduates had 2.8 jobs, with a median of 2 jobs. The people who have had up to 5 jobs represent $91 \%$ of our total sample.

Analysing the correspondence between the domain of work and school specialization, a third of our respondents work in other domains or specializations than the ones studied. The ones that work in the same specialization represent $20 \%$, as showed in Table 2.

Table 2: Correspondence between the domain of work and school specialization

\begin{tabular}{|l|l|}
\hline & $\mathbf{N} \%$ \\
\hline Domain of BA diploma (economy) & 45 \\
\hline The domain of the graduated specialization & 20 \\
\hline Other domain & 36 \\
\hline
\end{tabular}

Interpreting the results of the multiple logistic model

We have tested the impact of the independent variables on the dependent one using regression models in blocks. This allows us to note possible interactions between variables. 
Table 3: Regression models for over-qualification in blocks

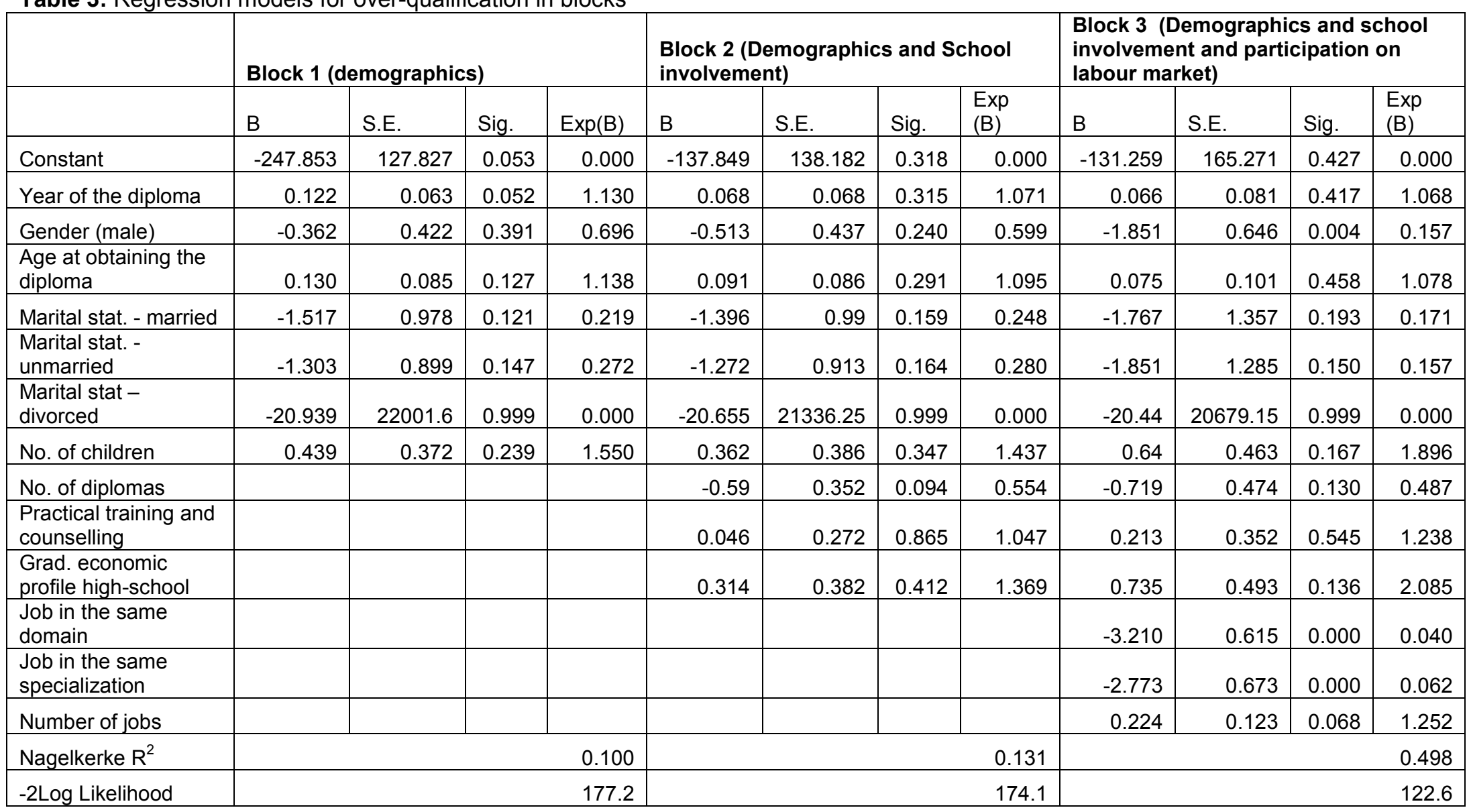


In the first block we have introduced the demographic variables: previous or independent from those related to both school trajectory and integration on the labour market. In the second block we have introduced variables related to school involvement, as proxies for motivation and school performance. In the last block we have included also the variables referring to the characteristics of the integration on the labour market. Table 3 presents the results of these analyses.

Surprisingly none of the independent variables included in the first two blocks (demographics and school involvement) had a significant impact on skills mismatch. Only the number of diplomas has a vaguely negative significant parameter $(p=0.094)$ : each extra diploma reduces with half the risk of over-qualification. This suggests a possible improvement of chances on the labour market, more precisely employment appropriate to qualification, for people getting more diplomas in higher education, independent of other characteristics of the person.

Including the variables regarding the integration on the labour market increases significantly the explanation level of the regression model (the two variables lead to an increase to 0.489 of $R^{2}$ Nagelkerke and reduce -2LL from 174 to 120 ). In this case, all the variables significantly affect the quality of employment and interact with other independent variables. Employment in the specialization or at least in the domain produces a dramatic decrease of the risk of having a job in an over-qualification situation. As expected, employment in other domains is related to high risks of having a job inferior to qualification. The number of jobs acquired by respondents before and during the survey has a strong relationship with the dependent variable: each extra job increases with $25 \%$ the risk of under-employment. This is an unexpected result as we would expect that graduates need to have several jobs until they find a good one. On the contrary, the statistical relationship is negative which indicates that the numerous changes of jobs do not represent attempts to find a good job, but rather attempts to adjust to the needs of the labour market for people with structural occupational problems.

Introducing these two variables in the analysis produces also an important change of the coefficient of gender which becomes significantly negative. In this model, the risk of being under-employed is reduced six times for men compared with women when all the other conditions are kept the same. By repeating, the last logistic regression without the number of jobs, we have confirmed that the significance of the impact of gender is revealed by the other variable: correspondence of the job with the domain and specialization of the studies. The analysis of the relationships between the three variables in multiple contingency tables allows also the understanding of the significant parameter of gender. Table 4 shows that, the control offered by the correspondence of work domain and specialization with the ones graduated, produce a positive association in the case of those who have jobs in other domains and specializations ( $p$ chi-square<0.05). In other words, women who find jobs outside their studies face a much higher risk of being hired in jobs with inferior qualification then the ones obtained by men.

Table 4: Association between gender and over-qualification, on levels of correspondence of domain and specialization of work with the ones graduated

\begin{tabular}{|l|l|l|c|c|l|}
\hline Job & Gender & $\begin{array}{l}\text { Number of } \\
\text { cases/Adjust } \\
\text { ed result }\end{array}$ & $\begin{array}{l}\text { Under-qualification } \\
\text { and } \\
\text { qualification }\end{array}$ & $\begin{array}{l}\text { Over- } \\
\text { qualified }\end{array}$ & Total \\
\hline \multirow{2}{*}{$\begin{array}{l}\text { In the same } \\
\text { domain }\end{array}$} & Male & $\mathrm{N}$ & 17 & 2 & 19 \\
\cline { 2 - 6 } & & Adj. res. & 0.2 & -0.2 & \\
\cline { 2 - 6 } & Female & $\mathrm{N}$ & 43 & 6 & 49 \\
\cline { 2 - 6 } & & Adj.res. & -0.2 & 0.2 & \\
\hline Total & & $\mathrm{N}$ & 60 & 8 & 68 \\
\hline
\end{tabular}




\begin{tabular}{|l|l|l|c|c|l|}
\hline \multirow{3}{*}{ Job } & Gender & $\begin{array}{l}\text { Number of } \\
\text { cases/Adjust } \\
\text { ed result }\end{array}$ & $\begin{array}{l}\text { Under-qualification } \\
\text { and appropriate } \\
\text { qualification }\end{array}$ & $\begin{array}{l}\text { Over- } \\
\text { qualified }\end{array}$ & Total \\
\hline \multirow{3}{*}{$\begin{array}{l}\text { In the same } \\
\text { specialization }\end{array}$} & Male & $\mathrm{N}$ & 4 & 0 & 4 \\
\cline { 2 - 6 } & & Adj.res. & 1 & -1 & \\
\cline { 2 - 6 } & Female & $\mathrm{N}$ & 21 & 5 & 26 \\
\cline { 2 - 6 } & & Adj.res. & -1 & 5 & 30 \\
\hline Total & & $\mathrm{N}$ & 25 & -2.3 & 20 \\
\hline \multirow{3}{*}{ Other } & Male & $\mathrm{N}$ & 11 & 26 & 34 \\
\cline { 2 - 7 } & & Adj.res. & 2.3 & 2.3 & \\
\cline { 2 - 6 } & & $\mathrm{N}$ & 8 & 35 & 54 \\
\hline Total & & $\mathrm{N}$ & -2.3 & 19 & \\
\hline
\end{tabular}

Note: For the first two categories $p>0.1$, and for the third (other) $p<0.05$.

\section{Conclusions and limits of the research}

The majority of hypotheses formulate for our multivariate model were refuted. Some of these negative results are at least as relevant as confirming the hypotheses. From our data there is no advantage on the labour market for the traditional students compared with the non-traditional - the probability of underemployment is not affected by the age at graduation, for example. On the other hand, none of the other demographic variables affect the probability to have a job corresponding to their qualification: marital status, number of children to not record significant parameters in the logistic regression model.

A relatively small number of variables explain almost half of the variation of the independent variable. The most important refers to having a job in the same domain or specialization. Finding a job outside the domain increases to $25 \%$ the risk of underemployment, this being the situation with the highest risk for our graduates. The analysis of having a job in or outside the domain reveals also a detail of the disadvantages of women on the labour market: solely outside the domain or the specialization of qualification the risk of under-employment is much higher for women compared to men. In the situations when graduates have jobs in their domain or within the specialization this difference is not significant. Finally, the number of jobs a person had before the current one also increases the risk of under-employment. This suggests that the numerous changes of jobs are correlated to some characteristics with a negative impact on the chances of employment of our graduates.

The main limits of this study derive from the non-random sampling method used to conduct analyses: subjects were auto-selected and consequently the representatively of the sample cannot be calculated. Some of the univariate descriptions indicated the directions of sampling distortions - older generations have smaller chances to enter the sample. This was not the case for the bi- and multivariate analyses in which the sampling biases do not interact with other correlations from the sample. Multivariate analyses aimed at explaining he situations of under- and over-qualification of our graduates, the conditions in which they get jobs inferior or superior to their qualification.

Our results have some practical consequences, especially for the counselling and vocational guidance of the faculty. As such, the most important service offered by the Faculty to its graduates is to offer help in finding a job correspondent to the domain and specialization of study. This can be achieved, at least partially, by a good relationship between the Faculty and employers, involving students in different activities for getting 
familiar with the realities of work, constant monitoring of employment offers in the domain by the counselling services of the faculty. Given the fact that, the chances of finding a job is influenced by transversal competences as well as personal characteristics - a part of the activities organized within the Faculty, through tutors, mentors, counsellors etc., should be targeted at improving these characteristics and overcoming shortcomings where these seriously affect student's employability. Finally, a special interest should be given to the disadvantage of women in situations of employment outside the domain: the phenomenon should be further investigated in order to explain the mechanism in which it is produced and consequently to adopt correct measures to prevent it.

\section{References}

Allen, J. and van der Velden, R. (2001). 'Educational mismatches versus skill mismatches: Effects on wages, job satisfaction, and on-the-job search', Oxford Economic Papers, vol. 53, no. 3, pp. 434-452.

Barone, C. and Ortiz, L. (2011). 'Overeducation among European university graduates: A comparative analysis of its incidence and importance of higher education differentiation', Higher Education, vol. 61, pp. 325-337.

Barone, C. and Schindler, S. (2014). Why does Field of Study Affect Occupational Attainment? A theoretical Approach, Rochester, NY: Social Science Electronic Publishing. Becker, G.S. (1964). Human Capital. A Theoretical and Empirical Analysis, with Special Reference to Education, Chicago, IL: The University of Chicago Press.

Castellano, R., Longobardi, S. and Rocca, A. (2014). 'Does education and skills mismatch affect gender wage gap? A decomposition analysis of PIAAC data for some European countries', Proceedings of the International Conference of Education, Research and Innovation, pp. 2609-2619.

CEDEFOP, (2014). Skill mismatch: more than meets the eye. [online]. Available at http://www.cedefop.europa.eu/files/9087 en.pdf. [02.05.2015].

Chevalier, A. and Lindley, J. (2009). Overeducation and the skills of UK graduates'. Journal of the Royal Statistical Society: Series A (Statistics in Society), Vol. 172, pp. 307-337.

Hannan, D., Raffe, D., and Smyth, E. (1997). 'Cross-national research on school to work transitions: An analytical framework', in P.Werquin, R. Breen and J. Planas (Eds.), Youth Transitions in Europe: Theory and Evidence, Marseilles: CEREQ.

Hatos. R. (2015). 'Skills mismatch of the young people at the European level', The Annals of the University of Oradea. Economic Sciences, Tom XIX, No. 1, pp. 431-440.

ILO, (2013). Global Employment Trends for Youth 2013: A generation at risk. Geneva: International Labor Office.

ILO, (2014). Skills mismatch in Europe. Statistics Brief. Geneva: International Labor Office. Kim, A. and Kim, K. (2003). 'Returns to tertiary education in Germany and the UK: Effects of field of study and gender', Mannheimer Zentrum Fur Europaische Sozialforschung, Working Paper No. 62.

Muresan. C. (2014). 'Postponement of motherhood in Romania: The role of educational attainment', Revista de Cercetare și de Intervenție Socială, ISSN: 1583-3410, vol. 47, pp. 137-149.

Ortiz, L. (2006). 'Finding a suitable job: The effect of the institutional context on selfperceived over-education', DemoSoc Working Paper, No. 14.

Reimer, D., Noelke, C. and Kucel, A. (2008). 'Labor market effects of field of study in comparative perspective: An analysis of 22 European countries', International Journal of Comparative Sociology vol. 49, no 4-5, pp.233-256. 
Saveanu T. and Saveanu, S. (2013). 'Volunteering among Students in Romania and Hungary Cross Border Area', The Annals of the University of Oradea. Economic Sciences, Tom XXII, No. 2, pp. 229-239.

Saveanu, T. and Saveanu, S. (2012). 'School Engagement, Work Values and Students' Training for the Labor Market', The Annals of the University of Oradea. Economic Sciences, Tom XXI, No. 1, pp. 414-420.

Van de Werfhorst, H.G. (2011). 'Skills, positional good or social closure? The role of education across structural-institutional labour market settings', Journal of Education and Work, vol. 24, no. 5, pp. 521-548.

Verhaest, D. and van der Velden, R. (2013). 'Cross-country differences in graduate overeducation', European Sociological Review, vol. 29, no. 3, pp. 642-653.

\section{Bio-note}

Roxana Hatos, Ph.D., is a researcher at the Faculty of Economics, Research Center for Competitiveness and Sustainable Development. Her PhD thesis was regarding: Youth on the labour market. Opportunities and difficulties of insertion. Some of her preoccupations are related to: youth on the labour market and skills mismatch.

Tomina Săveanu, Ph.D., is a researcher at the Faculty of Economics, Research Center for Competitiveness and Sustainable Development, and member of numerous research and development projects run within this Faculty. Some of her preoccupations are related to identifying means of improving the training of economic sciences graduates in order to ensure a better integration on the labour market. 